\title{
Development and Validation of a Stability Indicating RP-HPLC Method for the Determination of Two Sun Protection Factors (Koptrizon and Tinosorb S) in Topical Pharmaceutical Formulations Using Experimental Designs
}

\author{
Chinmoy Roy ${ }^{1,2}$ and Jitamanyu Chakrabarty ${ }^{2}$ \\ ${ }^{1}$ Analytical Research and Development, Dr. Reddy's Laboratories Ltd., Bachupally, Hyderabad, Andhra Pradesh 500090, India \\ ${ }^{2}$ Department of Chemistry, National Institute of Technology, Durgapur, West Bengal 713209, India
}

Correspondence should be addressed to Chinmoy Roy; chinmoyanalyst@gmail.com

Received 11 March 2013; Accepted 15 April 2013

Academic Editors: C. Akbay and J. A. P. Coelho

Copyright (C) 2013 C. Roy and J. Chakrabarty. This is an open access article distributed under the Creative Commons Attribution License, which permits unrestricted use, distribution, and reproduction in any medium, provided the original work is properly cited.

\begin{abstract}
A novel, simple, validated stability indicating HPLC method was developed for determination of Koptrizon and Tinosorb S. Stability indicating power of the method was established by forced degradation study. The chromatographic separation was achieved with Waters X Bridge C18 column, by using mobile phase consisting of a mixture of acetonitrile : tetrahydrofuran : water $(38: 38: 24$, $\mathrm{v} / \mathrm{v} / \mathrm{v})$. The method fulfilled validation criteria and was shown to be sensitive, with limits of detection (LOD) and quantitation (LOQ) of 0.024 and $0.08 \mu \mathrm{g} \mathrm{mL}^{-1}$ for Koptrizon and 0.048 and $0.16 \mu \mathrm{g} \mathrm{mL}^{-1}$ for Tinosorb S, respectively. The developed method is validated for parameters like precision, accuracy, linearity, solution stability, specificity, and ruggedness as per ICH norms. Design expert with ANOVA software with linear model was applied and a $2^{3}$ full factorial design was employed to estimate the model coefficients and also to check the robustness of the method. Results of the two-level full factorial design, $2^{3}$ with 10 runs including two-centre-point analysis based on the variance analysis (ANOVA), demonstrated that all three factors, as well as the interactions between retention time of Koptrizon, Tinosorb S, and USP plate count for Koptrizon, are statistically significant.
\end{abstract}

\section{Introduction}

Frequent exposure to UV radiation causes pronounced harmful effects on human health. UV radiation-induced effects are manifested as acute responses, namely, sunburn, hyperplasia, and immunosuppressant, and as chronic responses, primarily photo carcinogenesis and photo ageing [1].

The molecules employed in cosmetic products to protect skin from the sun are classified as physical and chemical sunscreens. Physical sunscreens are represented mainly by zinc and titanium oxides which interrupt the path of UV light by scattering or reflection. Chemical sunscreens are generally aromatic compounds conjugated with an electrondonating group in "ortho" or "para" position and an electron acceptor group. This chemical structure favours electron delocalization and therefore helps excitation of molecules from ground state to an excited state. The energy required for this transition corresponds to the energies of ultraviolet A (UVA) and Ultraviolet B (UVB) radiations [2,3].

Chronic exposure to UVB $(280-320 \mathrm{~nm})$ wavelengths induces damage to human skin, such as burns and erythema, but increases evidence of demonstrates that UVA radiation $(320-400 \mathrm{~nm})$ contributes to photo aging, which results in the accumulation of massive amounts of abnormal elastic material in the dermis of photo-aged skin and modification in collagen structure [4-6].

The use of sunscreen products is a widely accepted way of primary prevention against the harmful effects of solar radiation. To limit sun exposure, one is advised to wear loose fitting, tightly woven clothing, to stay in the shade 
between 11 a.m. and 3 p.m., and to use a sunscreen with a sun protection factor (SPF) of 15 or higher liberally reapplying every $2 \mathrm{~h}$ or after working, swimming, playing, or exercising outdoors [7-9].

The necessity to provide high SPF and screening efficiency against both UVA and UVB wavelengths has led to the development of sunscreen formulations with multiple added sunscreen chemicals [10].

The literature survey reveals that several techniques have been reported such as derivative spectrophotometry [11], high performance thin layer chromatography (HPTLC) $[12,13]$, gas chromatography and GC-MS [14], High performance liquid chromatography (HPLC) [15-23], in vitro and in vivo assessment of skin penetration and systemic absorption in human volunteers $[24,25]$, and in vitro SPF determination by UV [26] for individual or combination of sunscreen agents in cosmetic products.

Koptrizon (KPT) or Ethylhexyl triazone chemically known as 4-[[4,6-bis[[4-(2-ethylhexoxy-oxomethyl)phenyl]amino]-1,3,5-triazin-2-yl]amino] benzoic acid 2-ethylhexyl ester (Figure 1(a)) is an oil-soluble UVB filter (maximum absorption $314 \mathrm{~nm}$ ) manufactured by BASF under the trade mark Uvinul T150 and used in cosmetic formulation at concentrations up to $5 \%$. Due to its insolubility in water and affinity to the skin keratin, it is particularly suitable for water-resistant products. Its excellent photostability and high absorption coefficient make it a valuable ingredient when a high SPF value is required [27].

Tinosorb S (TIN) or Bemotrizinol chemically known as 2,2' -[6-(4-methoxyphenyl)-1,3,5-triazine-2,4-diyl] bis $\{5$ [(2-ethylhexyl)oxy]phenol\} (Figure 1(b)) is an oil-soluble organic compound that is added to sunscreens to absorb UV rays. TIN is a broad-spectrum UV absorber, absorbing UVB as well as UVA rays. It has two absorption peaks, 310 and $340 \mathrm{~nm}$. It is highly photostable. TIN has strong synergistic effects on the SPF when formulated with Bisoctrizole, Ethylhexyl triazone, or Iscotrizinol. It is the most effective UV absorber available measured by SPF, based on the maximum concentration permitted by European legislation [28-31].

There is not any method reported to estimate sunscreen agents KPT and TIN simultaneously in sunscreen formulations. It is essential to have a good analysis method to provide assurance of quality and effectiveness of the products. The purpose of this research work is to develop simple, accurate, and stability indicating method for simultaneous determination of Koptrizon and Tinosorb $S$ in sunscreen formulations by HPLC. Design of experiment (DOE) technique was employed to study the effect of critical factors on the method performance.

The drug product stability guideline Q1A (R2) issued by the International Conference on Harmonization (ICH) [32] suggests that stress studies should be carried out on a drug to establish its inherent stability characteristics, leading to identification of degradation products and, hence, supporting the suitability of the proposed analytical procedures. It also requires that analytical procedures for testing the stability of samples should be stability indicating and should be fully validated.

\section{Experimental}

2.1. Materials and Reagents. Sunscreen topical formulation and placebo were provided by Dr. Reddy's Lab., India. Koptrizon (Potency 99.7\%) and Tinosorb S (Potency 99.1\%) working standards were provided by BASF, India. HPLC grade acetonitrile and tetrahydrofuran were purchased from Rankem, India. $0.2 \mu \mathrm{m}$ PTFE syringe filter and Also, $0.2 \mu \mathrm{m}$ Nylon syringe filter were procured from Millipore, India. Water for HPLC was generated using Milli-Q Plus water purification system (Millipore, Milford, MA, USA).

2.2. Chromatographic Conditions and Equipments. HPLC (Allaince Waters, with Empower 2 software), photo stability chamber (Sanyo, Leicestershire, UK), dry air oven (Cintex, Mumbai, India), XS205 dual range balance (Mettler Toledo), and Cintex digital water bath were used for specificity studies. All chromatographic experiments were performed in the isocratic mode. Separation was achieved on Waters X Bridge $\mathrm{C} 18(50 \times 4.6 \mathrm{~mm}, 3.5 \mu)$ column as stationary phase by using mixture of acetonitrile: tetrahydrofuran: water $(38: 38: 24$, $\mathrm{v} / \mathrm{v} / \mathrm{v})$ as mobile phase. Other parameters such as run time 6 minutes, $1.2 \mathrm{~mL} \mathrm{~min}^{-1}$ as flow rate, injection volume of $5 \mu \mathrm{L}$, and column temperature of $50^{\circ} \mathrm{C}$ were finalized during development. KPT and TIN were detected at $311 \mathrm{~nm}$. Mixture of tetrahydrofuran: acetonitrile $(80: 20, \% \mathrm{v} / \mathrm{v})$ was used as diluents.

The stress degraded samples and the solution stability samples were analyzed using a PDA detector covering the range of $200-400 \mathrm{~nm}$.

\subsection{Procedure}

2.3.1. Standard Solution Preparation. An accurately weighed $15 \mathrm{mg}$ each of KPT and TIN working standards was taken into $100 \mathrm{~mL}$ volumetric flasks. About $70 \mathrm{~mL}$ of diluent was added to this and sonicated in an ultrasonic bath to dissolve. We made up the volume with diluent, mixed well.

2.3.2. Sample Solution Preparation. An accurately weighed sample equivalent to $15 \mathrm{mg}$ of KPT and TIN was taken into $100 \mathrm{~mL}$ volumetric flask. About $70 \mathrm{~mL}$ of diluent was added to this and sonicated in an ultrasonic bath for $15 \mathrm{~min}$ with intermittent shaking. We made up the volume with diluent, mixed well. We filtered a portion of solution through $0.2 \mu \mathrm{m}$ Nylon syringe filter.

\section{Results and Discussion}

3.1. Method Development and Optimization. Prime objective of an RP-HPLC method development for determination of KPT and TIN in topical dosage form was that the method should be able to determine assay of drug in single run and should be accurate, reproducible, robust, and stability indicating. All degradation products from stress conditions should be well separated from each other. Method should be simple so that it can be useful in analytical research and quality control laboratory for routine use. Furthermore, primary 
<smiles>CCCCC(CC)COC(=O)c1ccc(Nc2nc(Nc3ccc(C(=O)OCC(CC)CCCC)cc3)nc(Nc3ccc(C(=O)OCC(CC)CCCC)cc3)n2)cc1</smiles>

(a)<smiles>CCCCC(CC)COc1ccc(-c2nc(-c3ccc(OC)cc3)nc(-c3ccc(OCC(CC)CCCC)cc3O)n2)c(O)c1</smiles>

(b)

Figure 1: Chemical structure of (a) Koptrizon and (b) Tinosorb S.

developed method was challenged by forced degradation as a prevalidation.

\subsection{Mobile Phase and Chromatographic Conditions Opti-} mization. Column selection and mobile phase selection were done simultaneously. A method development was started with Waters Symmetry C18 $50 \times 3.9 \mathrm{~mm}, 5 \mu \mathrm{m}$ column, as stationary phase. Mobile phase was buffer $(10 \mathrm{mM}$ ammonium formate $\mathrm{pH} 4.5$ by formic acid):1,4-Dioxane, $20: 80 \mathrm{v} / \mathrm{v}$; flow rate $1.0 \mathrm{~mL} \mathrm{~min}^{-1}$; column temperature $40^{\circ} \mathrm{C}$. Peak broadening with less plate count for both the peaks was observed. Further trial was carried out with different columns such as $\mathrm{X}$ Bridge $(50 \times 4.6 \mathrm{~mm}, 3.5 \mu)$ keeping mobile phase and rest of chromatographic conditions the same, and peak broadening with less plate count for both the peaks was observed. In the next trial, column was $\mathrm{X}$ Bridge $(50 \times 4.6 \mathrm{~mm}, 3.5 \mu)$ and mobile phase consisted of acetonitrile : tetrahydrofuran : water $(38: 38: 24, \mathrm{v} / \mathrm{v} / \mathrm{v})$; peak tailing for Tinosorb $S$ peak was observed. To reduce run time and improve TIN peak shape, an attempt was made by increasing column temperature to $45^{\circ} \mathrm{C}$ and flow rate to $1.2 \mathrm{~mL} \mathrm{~min}^{-1}$. Peak shape for TIN improved but run time did not reduce. Further trial was for reducing run time. To reduce run time, an attempt was made by increasing column temperature to $50^{\circ} \mathrm{C}$ and flow rate to $1.5 \mathrm{~mL} \mathrm{~min}^{-1}$. Good peak symmetry for both the peaks was observed for KPT and TIN with 6.0 minutes run time.The chromatogram is shown in Figure 2. Different ratios of acetonitrile: tetrahydrofuran were tried as diluent but recovery problem was encountered. With consideration of solubility of two components, acetonitrile : tetrahydrofuran $(20: 80, \% \mathrm{v} / \mathrm{v})$ was used as diluent and satisfactory recovery was achieved.

3.3. Analytical Method Validation. After satisfactory development of method, it was subjected to method validation as per ICH guideline [33]. The method was validated to demonstrate that it is suitable for its intended purpose by the standard procedure. Analytical method validation was carried out by means of system suitability, accuracy, precision, linearity, robustness, solution stability, and filter compatibility.

3.3.1. System Suitability. System suitability parameters were measured so as to verify the system, method, and column performance. The \% RSD (relative standard deviation) of KOP and TIN was calculated from peak area count of five replicate injections (standard preparation) to be below $0.20 \%$. Low values of \% RSD of replicate injections indicate that the system is precise. Results of other system suitability parameters such as theoretical plates tailing factor are presented in Table 1.

3.3.2. Specificity. Specificity is the ability of the method to measure the analyte response in the presence of its potential impurities [33]. Forced degradation studies were performed to demonstrate selectivity and stability indicating capability of the proposed RP-HPLC method. Figure 2 shows that there is not any interference at the RT (retention time) of KOP and TIN due to blank and placebo and degradation products. Placebo, standard, and sample chromatogramss are presented in Figures 2(a), 2(b), and 2(c), respectively. 
TABLE 1: System suitability results (precision, intermediate precision, and robustness).

\begin{tabular}{|c|c|c|c|c|c|c|}
\hline Parameter & $\begin{array}{l}\text { Theoretical plates } \\
\text { for KPT > } 2000\end{array}$ & $\begin{array}{l}\text { Tailing factor } \\
\text { for KPT } \leq 2.0\end{array}$ & $\begin{array}{c}\text { \% RSD* of standard } \\
\text { Area }(\mathrm{KPT}) \leq 2.0 \\
\end{array}$ & $\begin{array}{l}\text { Theoretical plates } \\
\text { for TIN > } 3000\end{array}$ & $\begin{array}{l}\text { Tailing factor } \\
\text { for } \text { TIN } \leq 2.0\end{array}$ & $\begin{array}{c}\text { \% RSD }{ }^{*} \text { of standard } \\
\text { Area }(\mathrm{TIN}) \leq 2.0\end{array}$ \\
\hline Precision & 3512 & 1.0 & 0.3 & 4363 & 0.9 & 0.3 \\
\hline Intermediate precision & 3912 & 1.0 & 0.2 & 4578 & 1.0 & 0.4 \\
\hline At $1.7 \mathrm{~mL} \mathrm{~min}^{-1}$ flow rate & 3163 & 1.0 & 0.3 & 3917 & 0.9 & 0.4 \\
\hline At $1.3 \mathrm{~mL} \mathrm{~min}^{-1}$ flow rate & 3802 & 1.0 & 0.2 & 4789 & 0.9 & 0.2 \\
\hline At $55^{\circ} \mathrm{C}$ column temp. & 3128 & 1.0 & 0.3 & 3938 & 0.9 & 0.1 \\
\hline At $45^{\circ} \mathrm{C}$ column temp. & 3757 & 1.0 & 0.3 & 4594 & 0.9 & 0.3 \\
\hline Mobile phase $\mathrm{THF}+5 \%$ & 3117 & 1.0 & 0.4 & 4070 & 0.9 & 0.5 \\
\hline Mobile phase THF $-5 \%$ & 3701 & 1.0 & 0.1 & 4416 & 0.9 & 0.3 \\
\hline
\end{tabular}

${ }^{*}$ Determined on five values. THF: tetrahydrofuran.

TABLE 2: Data of forced degradation study for Koptrizon and Tinosorb S.

\begin{tabular}{|c|c|c|c|c|c|c|c|c|}
\hline \multirow{2}{*}{ Stress conditions } & \multicolumn{4}{|c|}{ Koptrizon } & \multicolumn{4}{|c|}{ Tinosorb S } \\
\hline & PA & PTH & \% Deg. & Purity flag & PA & PTH & \% Deg. & Purity flag \\
\hline $\begin{array}{l}\text { Acidic hydrolysis } \\
\left(5(\mathrm{~N}) \mathrm{HCl} \text { at } 70^{\circ} \mathrm{C}, 5 \mathrm{hrs}\right)\end{array}$ & 0.088 & 0.326 & 2.5 & No & 0.097 & 0.302 & 1.4 & No \\
\hline $\begin{array}{l}\text { Alkaline hydrolysis } \\
\left(5(\mathrm{~N}) \mathrm{NaOH} \text { at } 70^{\circ} \mathrm{C}, 5 \mathrm{hrs}\right)\end{array}$ & 0.145 & 0.381 & 43.7 & No & 0.130 & 0.367 & 39.6 & No \\
\hline $\begin{array}{l}\text { Oxidation } \\
\left(30 \% \mathrm{H}_{2} \mathrm{O}_{2} \text { at } 70^{\circ} \mathrm{C}, 2 \mathrm{hrs}\right)\end{array}$ & 0.076 & 0.311 & 14.5 & No & 0.094 & 0.299 & 9.2 & No \\
\hline $\begin{array}{l}\text { Thermal exposed } \\
\text { (At } 105^{\circ} \mathrm{C}, 6 \mathrm{hrs} \text { ) }\end{array}$ & 0.071 & 0.306 & ND & No & 0.091 & 0.307 & $\mathrm{ND}$ & No \\
\hline $\begin{array}{l}\text { Photolytic exposed } \\
\text { (1.2 million lux hr visible light and } 200 \mathrm{wh} / \mathrm{m}^{2} \mathrm{UV} \text { light) }\end{array}$ & 0.089 & 0.341 & ND & No & 0.084 & 0.325 & ND & No \\
\hline
\end{tabular}

PA: purity angle; PTH: purity threshold; Deg.: degradation; ND: no degradation.

Significant degradation was observed when the drug product was subjected to oxidation $\left(30 \% \mathrm{v} / \mathrm{v} \mathrm{H}_{2} \mathrm{O}_{2}, 70^{\circ} \mathrm{C}, 2 \mathrm{~h}\right)$ and base hydrolysis $\left(5(\mathrm{~N}) \mathrm{NaOH}, 70^{\circ} \mathrm{C}, 5 \mathrm{~h}\right)$. Significant degradation was not observed when KOP and TIN were subjected to acid hydrolysis $\left(5(\mathrm{~N}) \mathrm{HCl}, 70^{\circ} \mathrm{C}, 5 \mathrm{~h}\right)$. Sample chromatogram for base degradation and peroxide oxidation studies are presented in Figure 2(d) and Figure 2(e), respectively. Also no significant degradation was observed when the drug product was photolytic exposed (1.2 million lux hours and $200 \mathrm{wh} \mathrm{m}^{-2}$ UV light) and thermal exposed $\left(105^{\circ} \mathrm{C}, 6 \mathrm{~h}\right)$. Peaks due to KOP and TIN were investigated for spectral purity in the chromatogram of all exposed samples and found spectrally pure. Peak purity angles were less than peak purity thresholds for KOP and TIN. The purity and assay of KOP and TIN were unaffected by the presence of impurities and degradation products, thus confirming the stability-indicating power of the developed method. Results from forced degradation study are given in Table 2 .

3.3.3. Method Precision (Repeatability). The precision of the assay method was verified by repeatability and by intermediate precision. Precision was investigated using sample preparation procedure for six real lotion samples and analysing by proposed method. The average $\%$ assay values $(n=6)$ of KOP and TIN were $102.4 \%, 99.2 \%$, and $98.8 \%$, respectively, with
RSD of less than $1.0 \%$. Intermediate precision (reproducibility) was studied using different columns and performing the analysis on different days. Results are presented in Table 3 along with precision data. Low values of $\%$ RSD indicate that the method is precise.

3.3.4. Accuracy. To confirm the accuracy of the proposed method, recovery experiments were carried out by standard addition technique. Three different levels (50\%, 100\%, and $150 \%$ ) of standards were added to preanalysed placebo samples in triplicate. The percentage recoveries of KOP and TIN at each level and each replicate were determined. The mean of percentage recoveries $(n=3)$ and the $\%$ RSD were calculated. The amount recovered was within $\pm 1 \%$ of the amount added, which indicates that the method is accurate and also there is no interference due to excipients present in topical formulation. The results of recoveries for assay are shown in Table 4.

3.3.5. Limit of Detection (LOD) and Quantification (LOQ). The LOD and LOQ were determined at a signal-to-noise ratio of $3: 1$ and $10: 1$, respectively, by injecting a series of dilute solutions with known concentrations. The limit of detection and limit of quantification values of KOP and TIN are reported in Table 3 . 


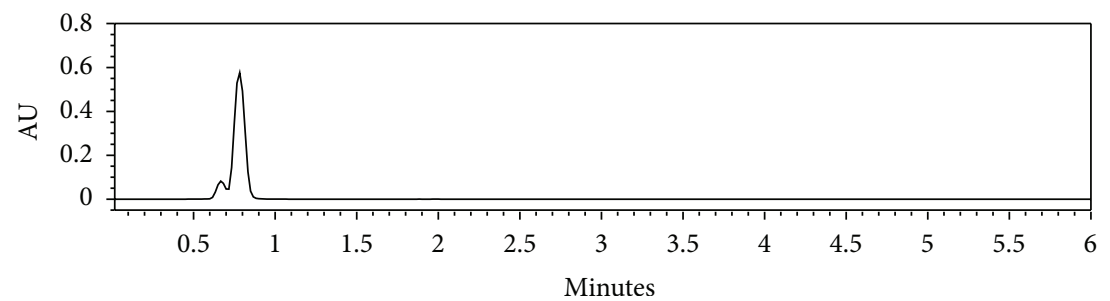

(a)

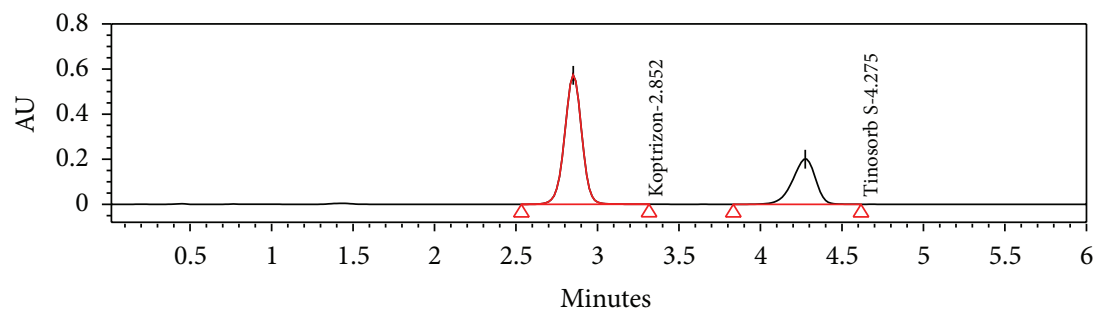

(b)

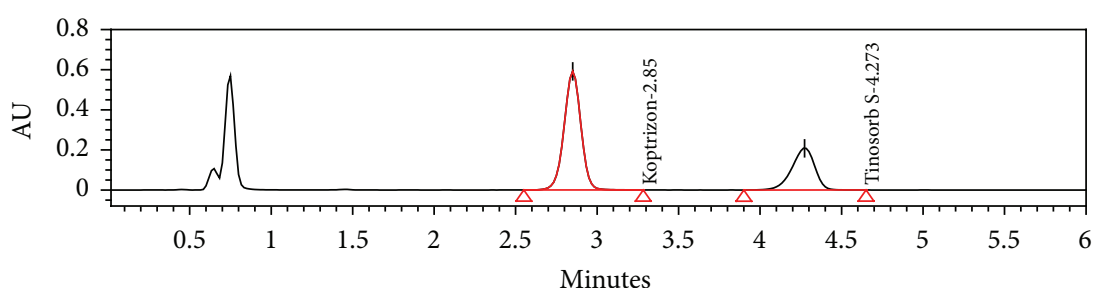

(c)

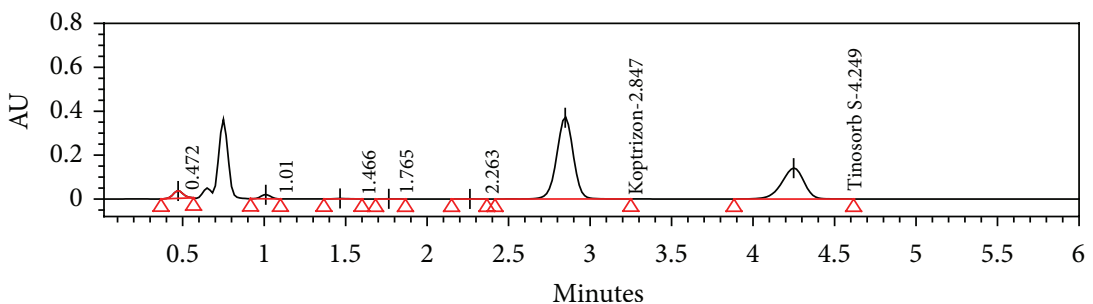

(d)

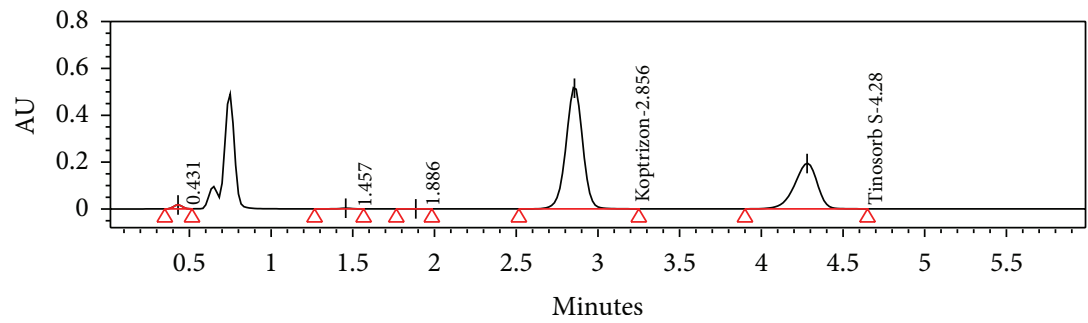

(e)

Figure 2: A typical chromatogram of (a) placebo (b) standard (c) sample (d) base degrdation sample and (e) peroxide degradation sample.

3.3.6. Linearity. Linearity was demonstrated from $50 \%$ to $150 \%$ of standard concentration using minimum five calibration levels $(50 \%, 75 \%, 100 \%, 125 \%$, and $150 \%)$ for the KOP and TIN compounds, which gave us a good confidence on analytical method with respect to linear range. The response was found linear for all KOP and TIN from 50\% to $150 \%$ of standard concentration, and correlation coefficient was greater than 0.999. Bias was also found within \pm 0.5 . The results of correlation coefficients, $Y$-intercept bias, and linearity equations for KOP and TIN are presented in Table 3.
3.3.7. Robustness. As defined by the $\mathrm{ICH}$, the robustness of an analytical procedure describes its capability to remain unaffected by small and deliberate variations in method parameters [33]. The robustness as a measure of method capacity to remain unaffected by small but deliberate changes in chromatographic conditions was studies by testing influence of small changes in flow rate $\left(1.5 \pm 0.2 \mathrm{~mL} \mathrm{~min}^{-1}\right)$, change in column oven temperature $\left(50 \pm 5^{\circ} \mathrm{C}\right)$, and change in mobile phase tetrahydrofuran composition (38 $\pm 5 \%)$. No significant effect was observed on system suitability 


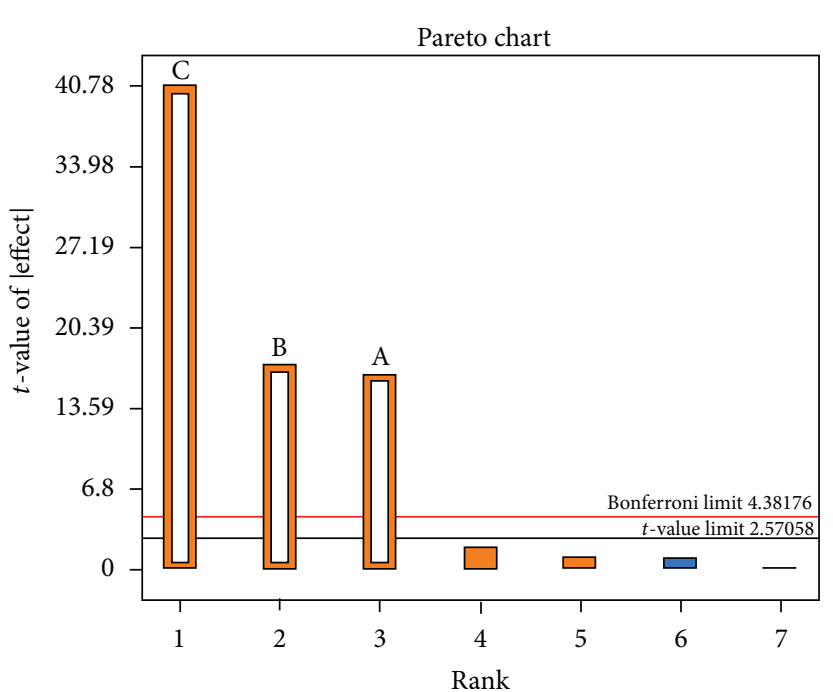

(a)

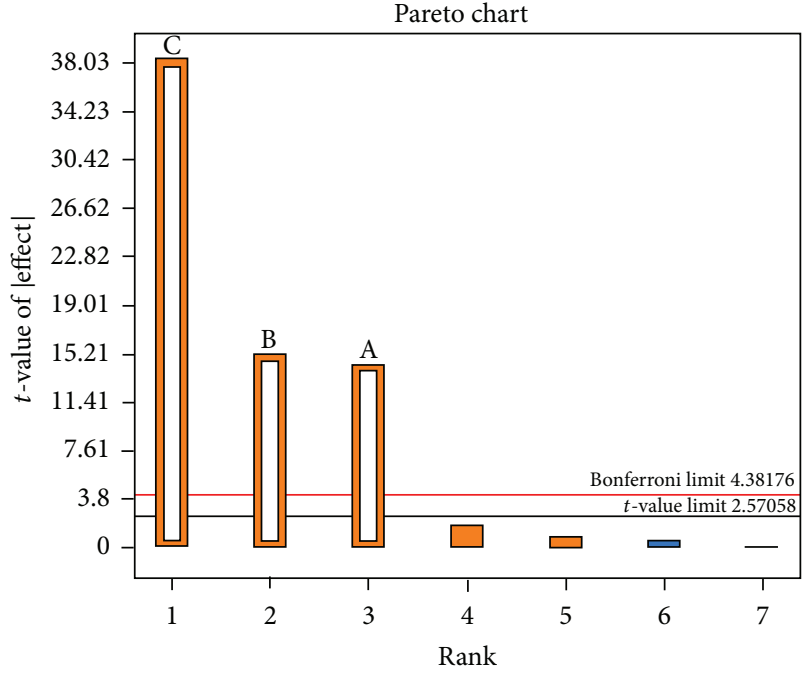

(b)

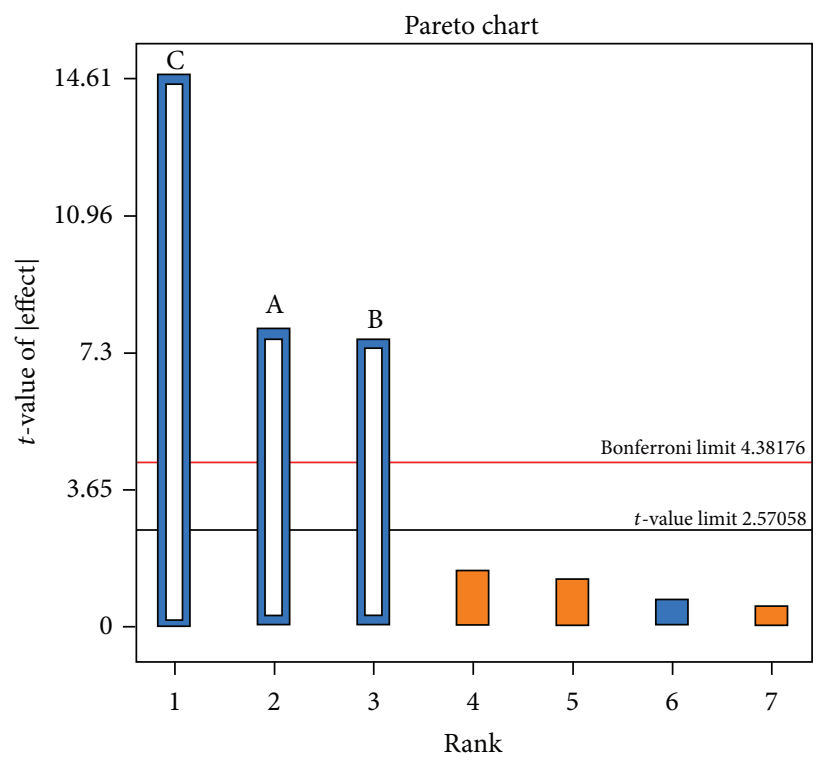

(c)

FIGURE 3: Pareto chart effect of factor (a) C > A > B in retention time of KPT, (b) C > B > A in retention time of TIN (c), and C > A $>$ B in plate count of KPT.

TABLE 3: Method precision, intermediate precision result, LOD, LOQ evaluations, and linearity data for KPT and TIN.

\begin{tabular}{lcc}
\hline Parameter & Koptrizon & Tinosorb S \\
\hline Precision Day-1/repeatability $(n=6)$ & $101.3 \pm 0.39 ; 0.38 ; 0.31$ & $100.2 \pm 0.51 ; 0.51 ; 0.41$ \\
$(\%$ Assay \pm SD; \% RSD; 95\% C.L. $)$ & $100.2 \pm 0.53 ; 0.53 ; 0.42$ & $99.9 \pm 0.29 ; 0.29 ; 0.24$ \\
Intermediate precision/reproducibility $(n=6)$ & 0.024 & 0.048 \\
$(\%$ Assay \pm SD; \% RSD; 95\% C.L. $)$ & 0.08 & 0.16 \\
LOD $\left(\mu \mathrm{g} \mathrm{m}^{-1}\right)$ & $0.08-225.8$ & $0.16-225.1$ \\
LOQ $\left(\mu \mathrm{g} \mathrm{m}^{-1}\right)$ & 0.99999 & 0.99999 \\
Linearity range $\left(\mu \mathrm{g} \mathrm{mL}^{-1}\right)$ & 2103.15 & 2032.08 \\
Correlation coefficient & 27767.747 & 13163.737 \\
Intercept $(a)$ & 0.050 & 0.102 \\
Slope $(b)$ & & \\
Bias at $100 \%$ response & & \\
\hline
\end{tabular}




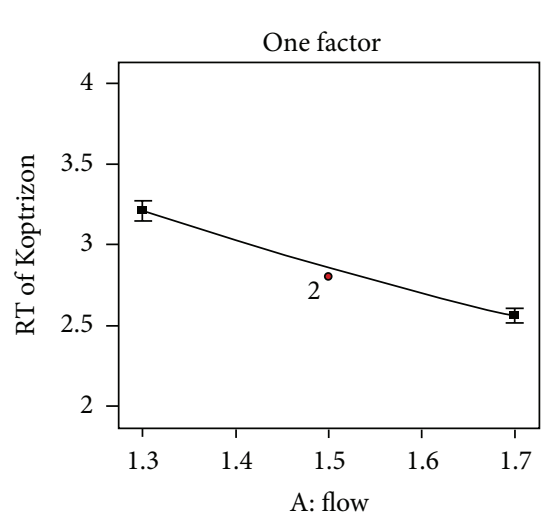

(a)

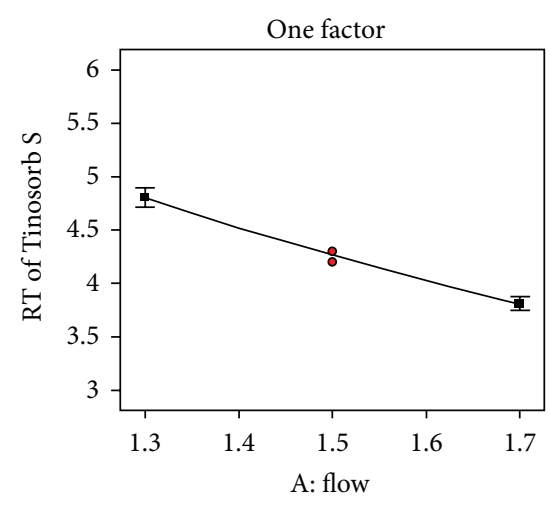

(d)

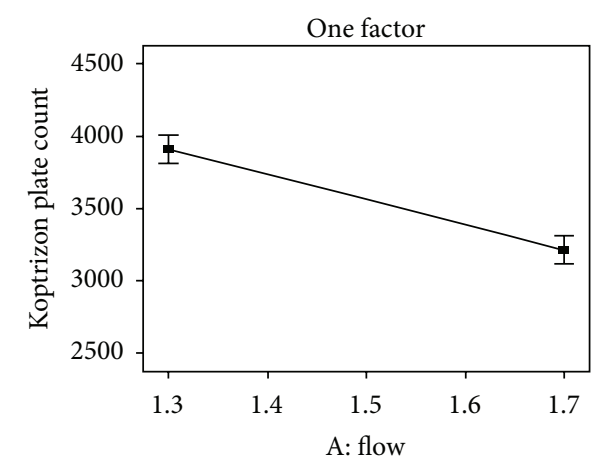

(g)

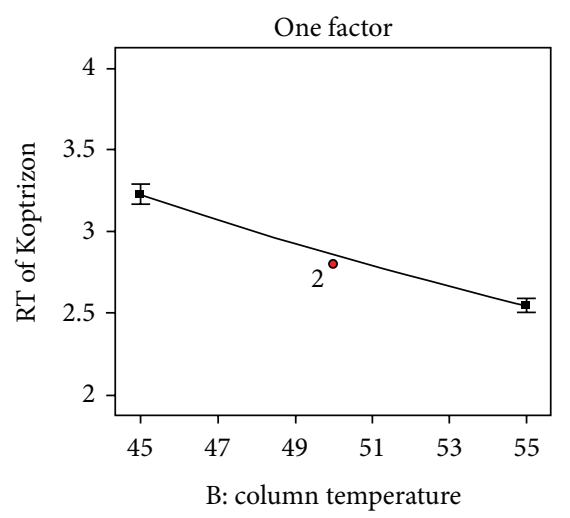

(b)

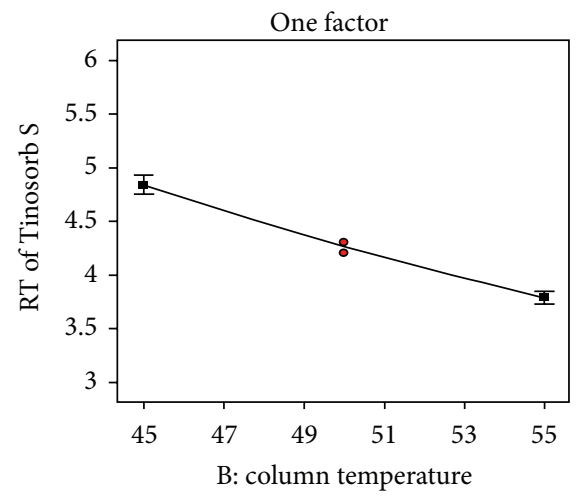

(e)

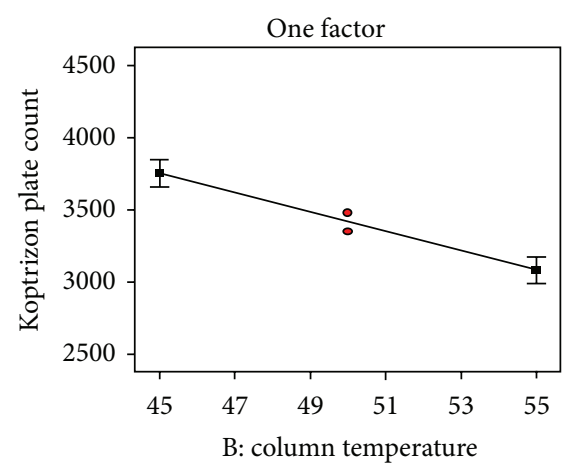

(h)

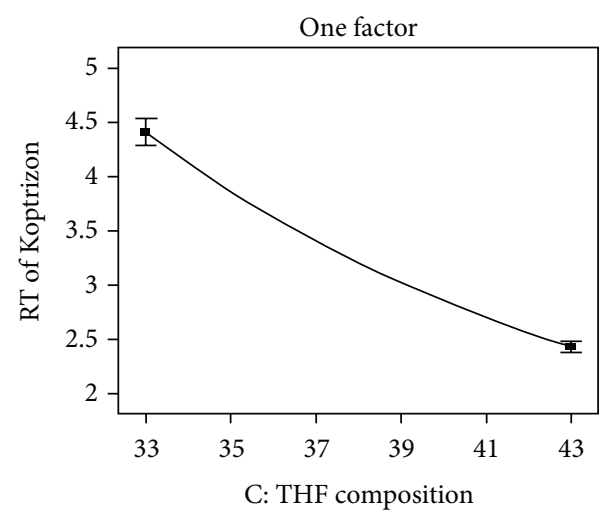

(c)

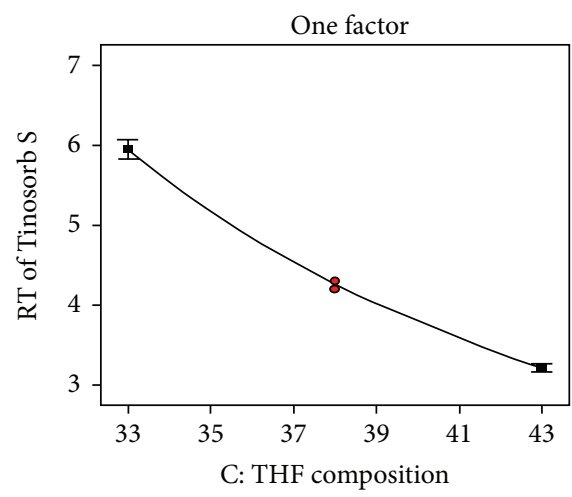

(f)

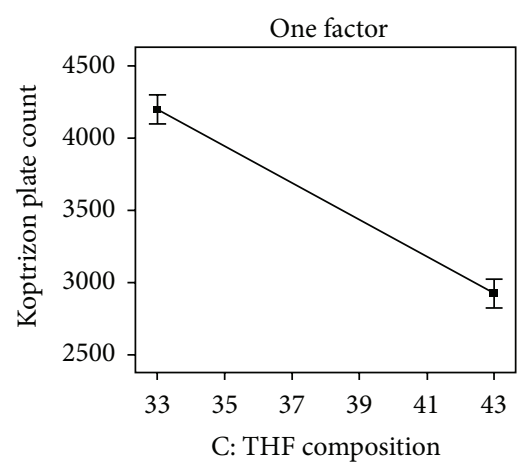

(i)

FIGURE 4: Single factor interaction: (a) flow rate in RT of KPT; (b) column temperature in KPT; (c) THF composition in KPT; (d) flow rate in RT of TIN; (e) column temperature in RT of TIN; (f) THF composition in RT of TIN; (g) flow rate in USP plate count of KPT; (h) column temperature in USP plate count of KPT; (i) THF composition in USP plate count KPT.

parameters such as theoretical plates and tailing factor. RSD of KOP and TIN was calculated from peak area count of five replicate injections, when small but deliberate changes were made to chromatographic conditions. The results are presented in Table 1 along with system suitability parameters of precision and intermediate precision study. Thus, the method was found to be robust with respect to variability in previous conditions.

3.3.8. Experimental Design Approach. Design Expert Software (Stat-Ease Inc., Statistic made easy, Minneapolis, MN, USA, version 7.0.0) was used for the experimental design throughout this screening process study. The full factorial design requires fewer measurements than the classical oneat-a-time experiment to give the same precision. At the same time, it detects and estimates any interaction between the factors. In order to study the simultaneous variation of the factors on the considered responses, a multivariate approach using design of experiments is recommended in robustness testing. However, if an analytical method is fast and requires the testing of a few factors (three or less), a good choice for robustness testing may be design expert, widely employed because of its high efficiency with respect to lesser number of runs required in full factorial mode. In 


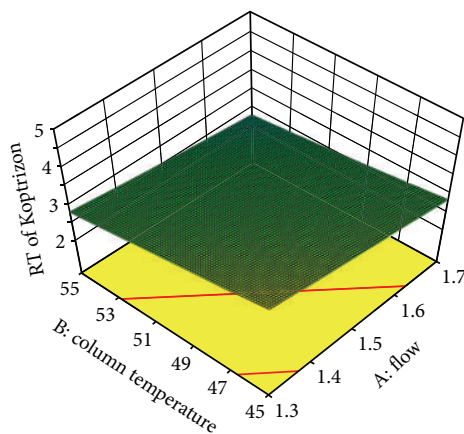

(a)

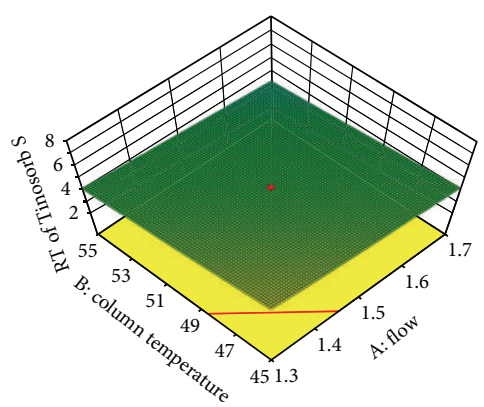

(d)

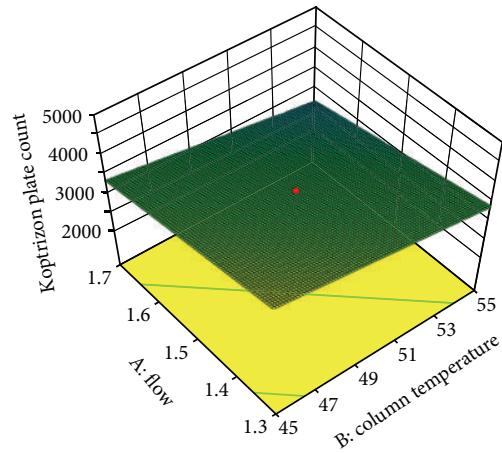

(g)

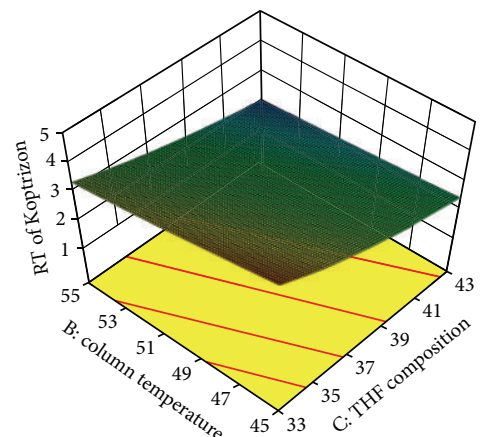

(b)

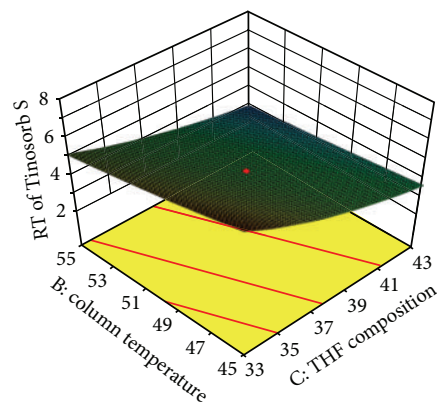

(e)

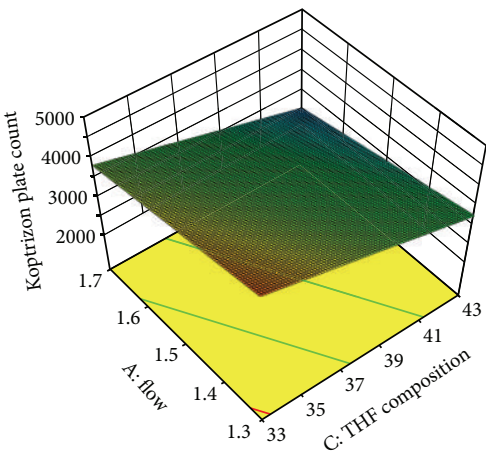

(h)

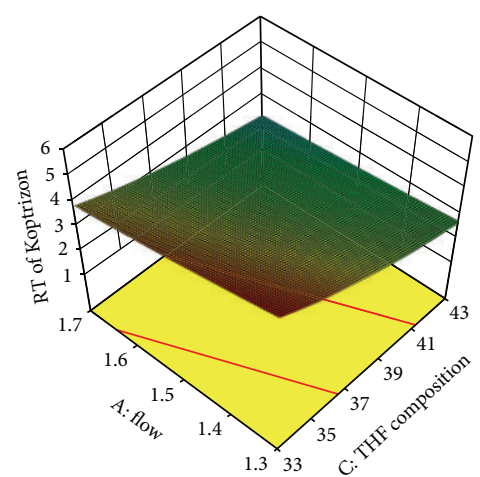

(c)

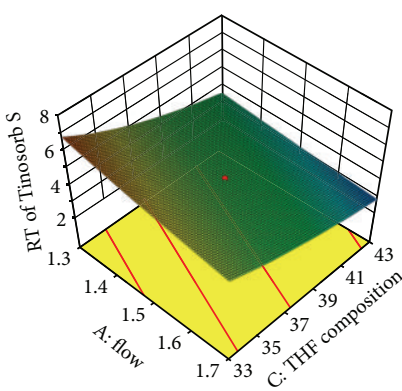

(f)

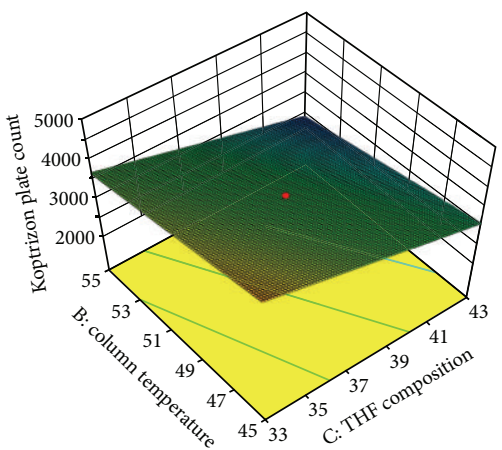

(i)

FIgURE 5: Three-dimensional plot of the fully factorial for predicted response RT of KPT plotted on $y$-axis as a function of factor. (a) A (flow rate) and B (column temperature); fixed factor: C (\% tetrahydrofuran 38.0\%). (b) B (column temperature) and C (\% tetrahydrofuran); fixed factor: A (flow rate $1.5 \mathrm{~mL} \mathrm{~min}^{-1}$ ). (c) A (flow rate) and $\mathrm{C}$ (\% tetrahydrofuran); fixed factor: B (column temperature $50^{\circ} \mathrm{C}$ ). RT of TIN plotted on $y$-axis as a function of factor. (d) A (flow rate) and B (column temperature); fixed factor: C (\% tetrahydrofuran 38.0\%). (e) B (column temperature) and $\mathrm{C}$ (\% tetrahydrofuran); fixed factor: A (flow rate $1.5 \mathrm{~mL} \mathrm{~min}^{-1}$ ). (f) A (flow rate) and C (\% tetrahydrofuran); fixed factor: B (column temperature $50^{\circ} \mathrm{C}$ ). Plate count of KPT plotted on $y$-axis as a function of factor. (g) A (flow rate) and B (column temperature); fixed factor: C (\% tetrahydrofuran 38.0\%). (h) A (flow rate) and C (\% tetrahydrofuran); fixed factor: B (column temperature $50^{\circ} \mathrm{C}$ ). (i) B (column temperature) and $\mathrm{C}$ (\% tetrahydrofuran); fixed factor: A (flow rate $1.5 \mathrm{~mL} \mathrm{~min}{ }^{-1}$ ).

order to study the three variables at two levels, the design used in robustness testing of KOP and TIN retention times and theoretical plate number for TIN was a $2^{3}$ full factorial design. ANOVA with linear model was applied to estimate the model coefficients and also check the robustness of the method. Three factors and two levels caused full factorial design $2^{3}$, in addition to that two centre points resulted total of ten experimental points-which were carried out in random order. Effect of two factors in the resulting RT responses of KPT, TIN and plate count of KPT shown in
Pareto chart (Figure 3). Three factors were considered: flow rate $\mathrm{mL} \mathrm{min}^{-1}(\mathrm{~A})$, column temperature (B), and tetrahydrofuran composition\% in mobile phase (C). The factors and level considered (responses) for the study are shown in Table 5. Standards and sample of KOP and TIN were prepared in assay concentration. The critical retention time for both KOP and TIN and also USP plate count for KOP peak were studied as response. All factors show negative effect in all three responses for one-factor-at-a-time response (Figure 4). 


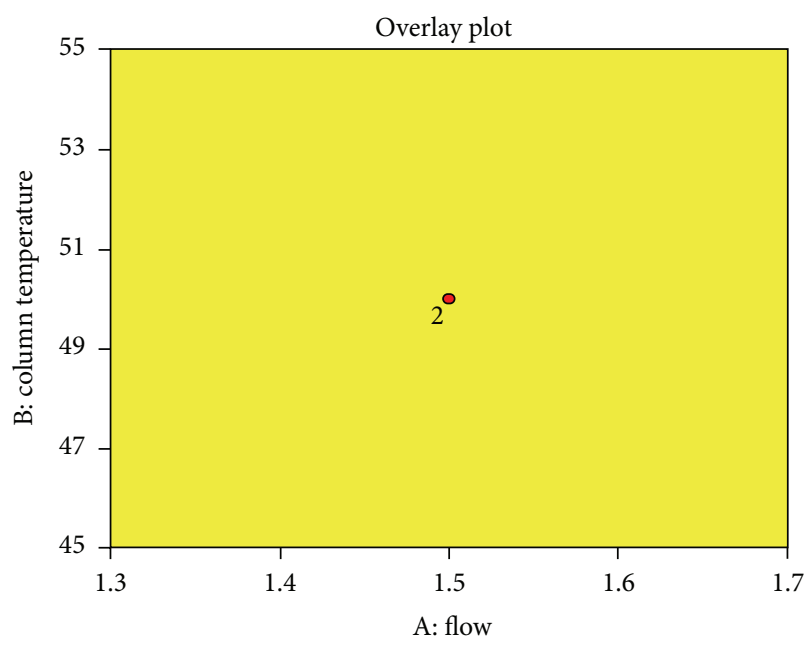

(a)

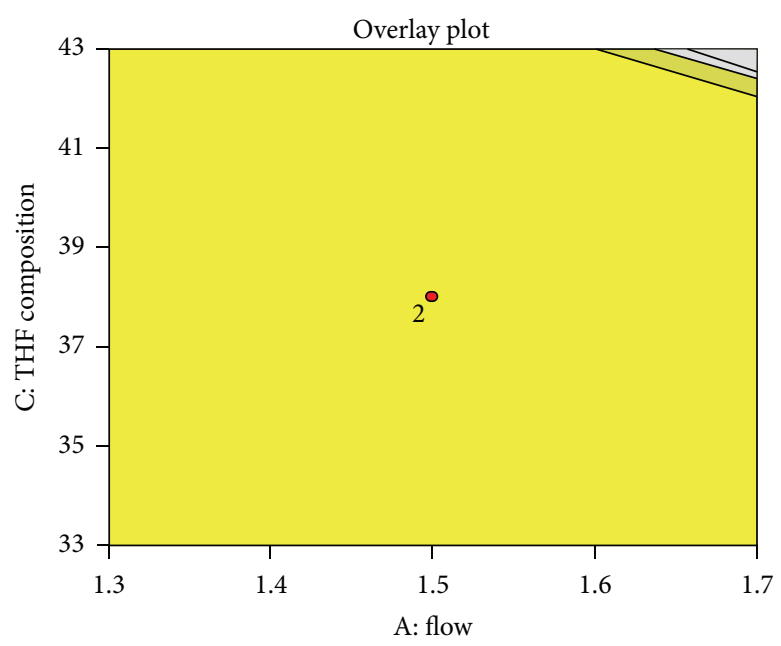

(b)

Figure 6: Graphical plot of the fully factorial design space for (a) changing factors A (flow rate) and B (column temperature); fixed factor: C (\% Tetrahydrofuran) (b) changing factors A (flow rate) and C (\% Tetrahydrofuran); fixed factor: B (column temperature).

TABLE 4: Accuracy results for Koptrizon and Tinosorb S $(n=3)$.

\begin{tabular}{lccc}
\hline $\begin{array}{l}\text { Active } \\
\text { components }\end{array}$ & $\begin{array}{c}\text { Amount added } \\
\left(\mu \mathrm{g} \mathrm{mL}^{-1}\right)\end{array}$ & $\begin{array}{c}\text { Amount } \\
\text { recovered } \\
\left(\mu \mathrm{g} \mathrm{mL}^{-1}\right)\end{array}$ & $\begin{array}{c}\text { \% Recovery } \pm \text { SD; } \\
\% \text { RSD }\end{array}$ \\
\hline \multirow{2}{*}{ KPT } & 74.9 & 75.4 & $100.7 \pm 0.63 ; 0.62$ \\
& 149.8 & 153.0 & $102.1 \pm 0.49 ; 0.48$ \\
& 224.7 & 220.4 & $98.1 \pm 0.53 ; 0.54$ \\
\hline \multirow{2}{*}{ TIN } & 75.6 & 75.5 & $99.0 \pm 0.00 ; 0.00$ \\
& 151.2 & 154.7 & $102.3 \pm 1.56 ; 1.52$ \\
& 226.8 & 222.7 & $98.2 \pm 0.33 ; 0.34$ \\
\hline
\end{tabular}

The ANOVA statistical test was employed to determine the significant and most contributing factors where they were ranked on the basis of degree of $F$ ratio. The higher the $F$ value corresponds with smaller "Prob $>F$ " value, the more significant are the resultant model and individual coefficient. Table 6 shows the reading of ANOVA analysis where $F$ value and $P$ value of the model were 743.3 and 0.0001 , respectively, demonstrating that the estimated model fits the experimental data satisfactorily. Also, the $R^{2}$ value was nearly close to 1 (0.99), which indicates that $99 \%$ of the data variability was successfully explained by the model. This means that with slight change of temperature, flow rate and $\%$ tetrahydrofuran composition in mobile phase during analysis, retention time (RT) of KPT will be affected. Hence, from this data generated by the model, it can be explained that RT of KPT is decreasing with increasing in mobile phase flow rate, column temperature and \% tetrahydrofuran composition as shown in Figures 5(a), 5(b), and 5(c). Table 7 shows the reading of ANOVA analysis where $F$-value and $P$-value of the model were 630.25 and 0.0001 , respectively, demonstrating that the estimated model fits satisfactorily with the experimental data. And also, the $R^{2}$ value was nearly close to 1 (0.99), which indicates that $98 \%$ of the data variability was successfully explained by the model. This means that with slight change of temperature, flow rate, and \% tetrahydrofuran composition in mobile phase during analysis, RT of TIN will be affected. Hence, from this data generated by the model, it explained that RT of TIN is decreasing with increasing in mobile phase flow rate, column temperature, and \% tetrahydrofuran composition as shown in Figures 5(d), 5(e), and 5(f). Table 8 shows the reading of ANOVA analysis where $F$-value and $P$-value of the model were 111.87 and 0.0001 , respectively, showing that the estimated model fits the experimental data satisfactorily. And also, the $R^{2}$ value was nearly close to $1(0.98)$, which indicates that $99 \%$ of the data variability was successfully explained by the model. This means that with slight change of temperature, flow rate, and \% tetrahydrofuran composition in mobile phase during analysis, the USP plate count of KPT will be affected. Hence, from this data generated by the model, it explained that plate count of KPT is decreasing with increasing in mobile phase flow rate, column temperature, and \% tetrahydrofuran composition as shown in Figures 5(g), $5(\mathrm{~h})$, and 5(i).

3.3.9. Design Space. DOE revolves around the concept of the design space, the multidimensional combination, and interaction of input variables and process parameters that have been demonstrated to provide assurance of quality. Working within the design space is not considered as a change. Movement out of the design space is considered to be a change and would normally initiate a regulatory postapproval change process. Design space is proposed by the applicant and is subject to regulatory assessment and approval [34-36]. Design space was established by employing full factorial design variables of flow rate (A) $1.3-1.7 \mathrm{~mL} \mathrm{~min}^{-1}$, column temperature (B) $45-55^{\circ} \mathrm{C}$, and $\%$ tetrahydrofuran composition in mobile phase (C) $33 \%-43 \%$ and their respective responses which are presented in Figure 6. 
TABLE 5: The range and levels of the variables in the $2^{3}$ full factorial design.

\begin{tabular}{|c|c|c|c|c|c|c|c|}
\hline Std. & Run & $\begin{array}{c}\text { Factor } 1 \\
\text { A: flow rate } \\
\left(\mathrm{mL} \mathrm{min}^{-1}\right)\end{array}$ & $\begin{array}{c}\text { Factor } 2 \\
\text { B: column temp } \\
\left({ }^{\circ} \mathrm{C}\right)\end{array}$ & $\begin{array}{c}\text { Factor } 3 \\
\text { C: } \text { THF comp } \\
(\%)\end{array}$ & $\begin{array}{c}\text { Response } 1 \\
\text { RT of KPT } \\
\quad(\mathrm{min})\end{array}$ & $\begin{array}{l}\text { Response } 2 \\
\text { RT of TIN } \\
\quad(\mathrm{min})\end{array}$ & $\begin{array}{c}\text { Response } 3 \\
\text { Plate count of KPT } \\
(\mathrm{min})\end{array}$ \\
\hline 0 & 2 & 1.5 & 50 & 38 & 2.8 & 4.3 & 3476 \\
\hline 0 & 7 & 1.5 & 50 & 38 & 2.8 & 4.2 & 3346 \\
\hline 7 & 1 & 1.3 & 55 & 43 & 2.2 & 3.2 & 2806 \\
\hline 4 & 3 & 1.7 & 55 & 33 & 3.1 & 4.7 & 3200 \\
\hline 2 & 4 & 1.7 & 45 & 33 & 3.9 & 6.0 & 4108 \\
\hline 6 & 5 & 1.7 & 45 & 43 & 2.2 & 3.2 & 2767 \\
\hline 8 & 6 & 1.7 & 55 & 43 & 1.8 & 2.6 & 2204 \\
\hline 3 & 8 & 1.3 & 55 & 33 & 3.8 & 5.8 & 4114 \\
\hline 5 & 9 & 1.3 & 45 & 43 & 2.8 & 4.1 & 3336 \\
\hline 1 & 10 & 1.3 & 45 & 33 & 5.1 & 7.9 & 4804 \\
\hline 0 & 2 & 1.5 & 50 & 38 & 2.8 & 4.3 & 3476 \\
\hline
\end{tabular}

TABLE 6: ANOVA for $2^{3}$ full factorial design: response: RT of Koptrizon (min).

\begin{tabular}{lccccc}
\hline Source & Sum of squares & df & Mean square & $F$ value & $P$ value prob $>F$ \\
\hline Model & 0.073284126 & 3 & 0.024428 & 743.3259616 & $<0.0001$ \\
$\quad$ A-flow & 0.008862903 & 1 & 0.008863 & 269.6911034 & $<0.0001$ \\
B-column temp. & 0.009766119 & 1 & 0.009766 & 297.1752743 & $<0.0001$ \\
C-THF comp. & 0.054655104 & 1 & 0.054655 & 1663.111507 & $<0.0001$ \\
Curvature & $8.82574 E-05$ & 1 & $8.83 E-05$ & 2.68560136 & 0.1622 \\
Residual & 0.000164316 & 5 & $3.29 E-05$ & & Not significant \\
Lack of fit & 0.000164316 & 4 & $4.11 E-05$ & & \\
Pure error & 0 & 1 & 0 & & \\
Cor total & 0.073536699 & 9 & & & \\
Std. dev. & 0.006488107 & & $R^{2}$ & 0.996565345 & \\
Mean & 0.591672677 & Adjusted $R^{2}$ & 0.994848018 & \\
\hline
\end{tabular}

Values of prob $>F$ less than 0.05 indicates that model is significant.

3.3.10. Stability of Sample Solution. Stability of sample solution was established by its storage at ambient temperature for $24 \mathrm{hrs}$. The assays of KOP and TIN were analysed. It was found that $\%$ labelled amounts of KOP at 0,12 , and $24 \mathrm{hrs}$ were $101.3,100.7$, and 101.6, respectively, and \% labelled amounts of TIN were $100.2,99.8$, and 99.7, respectively.

3.3.11. Filter Compatibility. Filter compatibility was performed for nylon $0.2 \mu \mathrm{m}$ syringe filter (Millipore) and PTFE $0.2 \mu \mathrm{m}$ syringe filter (Millipore). To confirm the filter compatibility in proposed method, filtration recovery experiment was carried out by sample filtration technique. Samples were filtered through both syringe filters and percentage assay was determined and compared against centrifuged sample. Sample solution did not show any significant change in assay percentage with respect to centrifuged sample. It was found that \% labelled amounts of KPT at centrifuged sample, $0.22 \mu \mathrm{m}$ nylon syringe filter, and $0.22 \mu \mathrm{m}$ PTFE syringe filter were $100.5,100.3$, and 99.8, respectively, and for TIN were $100.2,100.5$, and 100.5. In the result obtained, difference in $\%$ assay was not more than \pm 1.0 , which indicates that both syringe filters have good compatibility with sample.

\section{Conclusion}

The experimental design describes the key HPLC method components including column temperature, mobile phase flow rate, and \% tetrahydrofuran composition in mobile phase. The interrelationships are studied and the preliminary optimized conditions are obtained for each combination. Here a better understanding of the factors influencing chromatographic separation and greater confidence in the ability of the methods to meet their intended purposes is done. Moreover, this approach ensures better design of product. A gradient RP-HPLC method was successfully developed for the estimation of KOP and TIN in topical dosage form. The method validation results have proved that the method is selective, precise, accurate, linear, robust, filter compatible, and stability indicating. The drug is stable in thermal and photolytic conditions and degrades in acidic, basic, and oxidative conditions. The method robustness was demonstrated using experimental design techniques, taking into consideration the selectivity of the RP HPLC method. The short run time $(6.0 \mathrm{~min})$ enables rapid determination of drug. Moreover, it may be applied for determination 
TABLE 7: ANOVA for $2^{3}$ full factorial design: response: RT of Tinosorb S (min).

\begin{tabular}{lccccc}
\hline Source & Sum of squares & $\mathrm{df}$ & Mean square & $F$ value & $P$ value Prob $>F$ \\
\hline Model & 0.057184881 & 3 & 0.019061627 & 630.2536737 & $<0.0001$ \\
$\quad$ A-flow & 0.006317517 & 1 & 0.006317517 & 208.8823992 & $<0.0001$ \\
B-column temp. & 0.007126362 & 1 & 0.007126362 & 235.6260641 & $<0.0001$ \\
$\quad$ C-THF comp. & 0.043741001 & 1 & 0.043741001 & 1446.252558 & $<0.0001$ \\
Curvature & $1.67021 E-06$ & 1 & $1.67021 E-06$ & 0.055223918 & 0.8235 \\
Residual & 0.000151222 & 5 & $3.02444 E-05$ & & 0.4746 \\
Lack of fit & 0.000134936 & 4 & $3.37339 E-05$ & 2.071326494 & Not significant \\
Pure error & $1.62861 E-05$ & 1 & $1.62861 E-05$ & & \\
Cor total & 0.057337773 & 9 & & & \\
Std. dev. & 0.005047971 & & $R^{2}$ & 0.997333484 & \\
Mean & 0.484279065 & & Adjusted $R^{2}$ & 0.996000226 & \\
\hline
\end{tabular}

Values of prob $>F$ less than 0.05 indicates that model is significant.

TABLE 8: ANOVA for $2^{3}$ full factorial design: response: Koptrizon plate count.

\begin{tabular}{lccccc}
\hline Source & Sum of squares & $\mathrm{df}$ & Mean square & $F$ value & $P$ value Prob $>F$ \\
\hline Model & 5139776.375 & 3 & 1713258.792 & 111.8731376 & $<0.0001$ \\
A-flow & 966745.125 & 1 & 966745.125 & 63.12695487 & 0.0005 \\
B-column temp. & 905185.125 & 1 & 905185.125 & 59.1071825 & 0.0006 \\
C-THF comp. & 3267846.125 & 1 & 3267846.125 & 213.3852755 & $<0.0001$ \\
Curvature & 65.025 & 1 & 65.025 & 0.004246031 & 0.9506 \\
Residual & 76571.5 & 5 & 15314.3 & & 0.4800 \\
Lack of fit & 68121.5 & 4 & 17030.375 & 2.015428994 & Not significant \\
Pure error & 8450 & 1 & 8450 & & \\
Cor total & 5216412.9 & 9 & & & \\
Std. dev. & 113.0166101 & & $R^{2}$ & 0.985308578 & \\
Mean & 3416.1 & Adjusted $R^{2}$ & 0.977962866 & \\
\hline
\end{tabular}

Values of prob $>F$ less than 0.05 indicates that model is significant.

of KOP and TIN in the study of content uniformity, tube homogeneity, and in vitro release test profiling of KOP and TIN topical dosage forms, where sample load is higher and high throughput is essential for faster delivery of results.

\section{Conflict of Interests}

The authors of the paper declare that there is no direct financial relation with the commercial identities mentioned in the paper that might lead to a conflict of interests.

\section{Acknowledgments}

The authors would like to thank M/s. Dr. Reddy's Laboratories Ltd. for supporting this work. The authors' Intellectual Property Management (IPM) department has given this paper internal publication no. PUB00228-13.

\section{References}

[1] A. Chisvert, M. C. Pascaul-Marti, and A. Salvador, "Determination of the UV filters worldwideauthorized in sunscreens by HPLC Use of cyclodextrins as mobile phase modifier," Journal of Chromatography A, vol. 921, no. 2, pp. 207-215, 2001.
[2] C. Couteau, A. Faure, J. Fortin, E. Paparis, and L. J. M. Coiffard, "Study of the photostability of 18 sunscreens in creams by measuring the SPF in vitro," Journal of Pharmaceutical and Biomedical Analysis, vol. 44, no. 1, pp. 270-273, 2007.

[3] A. Salvador and A. Chisvert, "Sunscreen analysis: a critical survey on UV filters determination," Analytica Chimica Acta, vol. 537, no. 1-2, pp. 1-14, 2005.

[4] B. A. Gilchrest, N. A. Soter, J. L. Hawk et al., "Histological changes associated with ultraviolet A-induced erythema in normal human skin," Journal of the American Academy of Dermatology, vol. 9, no. 2, pp. 213-219, 1983.

[5] T. Takeuchi, J. Uitto, and E. F. Bernstein, "A novel in vivo model for evaluating agents that protect against ultraviolet A-induced photoaging," Journal of Investigative Dermatology, vol. 110, no. 4, pp. 343-347, 1998.

[6] J. M. Menter, A. M. Patta, R. M. Sayre, J. Dowdy, and I. Willis, "Effect of UV irradiation on type I collagen fibril formation in neutral collagen solutions," Photodermatology Photoimmunology and Photomedicine, vol. 17, no. 3, pp. 114-120, 2001.

[7] 2010, http://www.who.int/uv/sun_protection/en/.

[8] A. Rampaul, I. P. Parkin, and L. P. Cramer, "Damaging and protective properties of inorganic components of sunscreens applied to cultured human skin cells," Journal of Photochemistry and Photobiology A, vol. 191, no. 2-3, pp. 138-148, 2007. 
[9] L. M. Peruchi and S. Rath, "Development and application of a HPLC method for eight sunscreen agents in suncare products," International Journal of Cosmetic Science, vol. 34, no. 1, pp. 226233, 2012.

[10] J. Flor, M. R. Davolos, and M. A. Correa, "Sunscreens," Quimica Nova, vol. 30, no. 1, pp. 153-158, 2007.

[11] H. M. Chawla and S. Mrig, "Simultaneous quantitative estimation of oxybenzone and 2-ethylhexyl-4- methoxycinnamate in sunscreen formulations by second order derivative spectrophotometry," Journal of Analytical Chemistry, vol. 64, no. 6, pp. 585$592,2009$.

[12] E. Westgate and J. Sherma, "Determination of the sunscreen oxybenzone in lotions by reversed-phase HPTLC with ultraviolet absorption densitometry," Journal of Liquid Chromatography and Related Technologies, vol. 23, no. 4, pp. 609-615, 2000.

[13] A. W. Sobanska and E. Brzezinska, "Normal-phase TLC analysis of UV filters avobenzone and octocrylene in sunscreen preparations," Journal of Planar Chromatography, vol. 24, no. 2, pp. 154-159, 2011.

[14] K. Ikeda, S. Suzuki, and Y. Watanabe, "Determination of sunscreen agents in cosmetic products by reversed-phase highperformance liquid chromatography," Journal of Chromatography, vol. 513, pp. 321-326, 1990.

[15] L. Dencausse, A. Galland, J. L. Clamou, and J. Basso, "Validation of HPLC method for quantitative determination of Tinosorb $₫ S$ and three other sunscreens in a high protection cosmetic product," International Journal of Cosmetic Science, vol. 30, no. 5, pp. 373-382, 2008.

[16] A. Salvador and A. Chisvert, "An environmentally friendly ("green") reversed-phase liquid chromatography method for UV filters determination in cosmetics," Analytica Chimica Acta, vol. 537, no. 1-2, pp. 15-24, 2005.

[17] E. R. M. Kedor-Hackmann, M. L. De Lourdes Pérez González, A. K. Singh, and M. I. R. M. Santoro, "Validation of a HPLC method for simultaneous determination of five sunscreens in lotion preparation," International Journal of Cosmetic Science, vol. 28, no. 3, pp. 219-224, 2006.

[18] S. Scalia, "Determination of sunscreen agents in cosmetic products by supercritical fluid extraction and high-performance liquid chromatography," Journal of Chromatography A, vol. 870, no. 1-2, pp. 199-205, 2000.

[19] S. Simeoni, R. Tursilli, A. Bianchi, and S. Scalia, "Assay of common sunscreen agents in suncare products by highperformance liquid chromatography on a cyanopropyl-bonded silica column," Journal of Pharmaceutical and Biomedical Analysis, vol. 38, no. 2, pp. 250-255, 2005.

[20] M. Nyeborg, M. Pissavini, Y. Lemasson, and O. Doucet, "Validation of HPLC method for the simultaneous and quantitative determination of 12 UV-filters in cosmetics," International Journal of Cosmetic Science, vol. 32, no. 1, pp. 47-53, 2010.

[21] M. Wharton, M. Geary, N. O'Connor, and B. Murphy, "A rapid High Performance Liquid Chromatographic (HPLC) method for the simultaneous determination of seven UV filters found in sunscreen and cosmetics," International Journal of Cosmetic Science, vol. 33, no. 2, pp. 164-170, 2011.

[22] F. M. P. Vilela, Y. M. Fonseca, F. T. M. C. Vicentini, M. J. V. Fonseca, and M. D. P. H. Do Amaral, "Determination of three ultraviolet filters in sunscreen formulations and from skin penetration studies by high-performance liquid chromatography," Quimica Nova, vol. 34, no. 5, pp. 879-883, 2011.
[23] A. W. Sobanska and J. Pyzowski, "Quantification of sunscreen ethylhexyl triazone in topical skin-care products by normalphase TLC/densitometry," Scientific World Journal, vol. 2012, Article ID 807516, 6 pages, 2012.

[24] G. Potard, C. Laugel, H. Schaefer, and J. P. Marty, “The stripping technique: in vitro absorption and penetration of five UV filters on excised fresh human skin," Skin Pharmacology and Applied Skin Physiology, vol. 13, no. 6, pp. 336-344, 2000.

[25] G. Potard, C. Laugel, A. Baillet, H. Schaefer, and J. P. Marty, "Quantitative HPLC analysis of sunscreens and caffeine during in vitro percutaneous penetration studies," International Journal of Pharmaceutics, vol. 189, no. 2, pp. 249-260, 1999.

[26] M. D. Bleasel and S. Aldous, "In vitro evaluation of sun protection factors of sunscreen agents using a novel UV spectrophotometric technique," International Journal of Cosmetic Science, vol. 30, no. 4, pp. 259-270, 2008.

[27] Uvinul grades, UV absorbers for cosmetic products, BASF technical information.

[28] G. Vielhaber, S. Grether-Beck, O. Koch, W. Johncock, and J. Krutmann, "Sunscreens with an absorption maximum of $\geq 360 \mathrm{~nm}$ provide optimal protection against UVA1-induced expression of matrix metalloproteinase-1, interleukin-1, and interleukin-6 in human dermal fibroblasts," Photochemical and Photobiological Sciences, vol. 5, no. 3, pp. 275-282, 2006.

[29] E. Chatelain and B. Gabard, "Photostabilization of butyl methoxydibenzoylmethane (Avobenzone) and Ethylhexyl methoxycinnamate by bis-ethylhexyloxyphenol methoxyphenyl triazine (Tinosorb S), a new UV broadband filter," Photochemical and Photobioogical Sciences, vol. 74, no. 3, pp. 401-406, 2001.

[30] http://www.ciba.com/tinosorb-s_brochure.pdf.

[31] C. Couteau, M. Pommier, E. Paparis, and L. J. M. Coiffard, "Study of the efficacy of 18 sun filters authorized in European Union tested in vitro," Pharmazie, vol. 62, no. 6, pp. 449-452, 2007.

[32] ICH Q1A (R2), "Stability Testing of new Drug Substances and Products," in Proceedings of the International Conference on Harmonization, 2003.

[33] ICH Q2 (R1), "Validation of analytical procedures: text and methodology," in Proceedings of the International Conference on Harmonization, 2005.

[34] J. Peterson, "Statistical Analysis QbD Classics: What Your ICH Q8 Design Space Needs," Pharma Qbd, 2010.

[35] U. Smith, "Optimizing Design of Experiments for Fluid Bed Coating," Pharma Qbd, 2010.

[36] M. Anderson, "Design space, Framing a QbD Design Space with Tolerance Intervals," Pharma Qbd, 2012. 

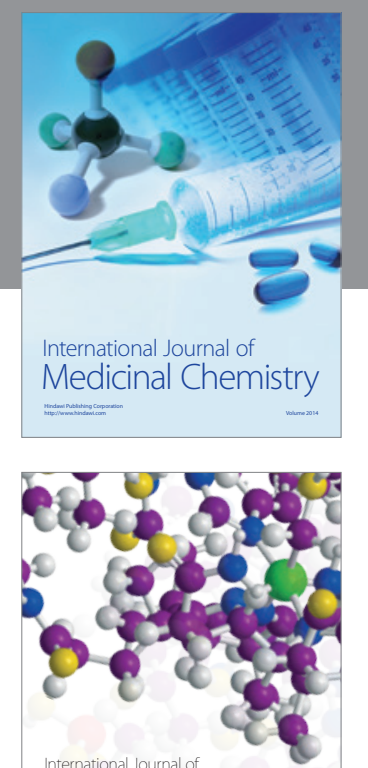

\section{Carbohydrate} Chemistry

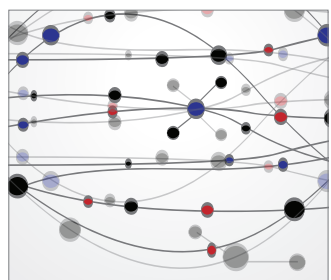

The Scientific World Journal
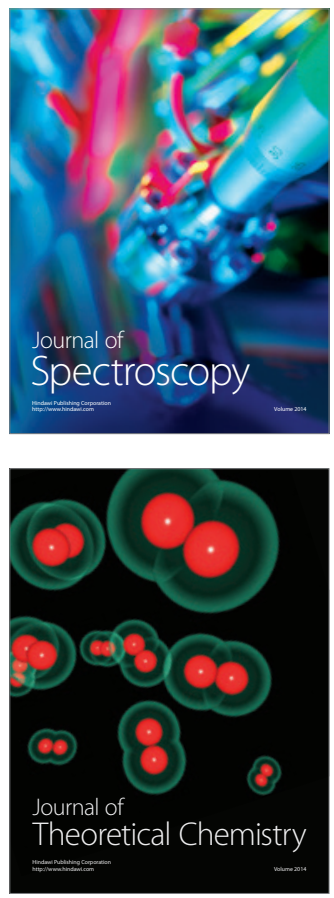
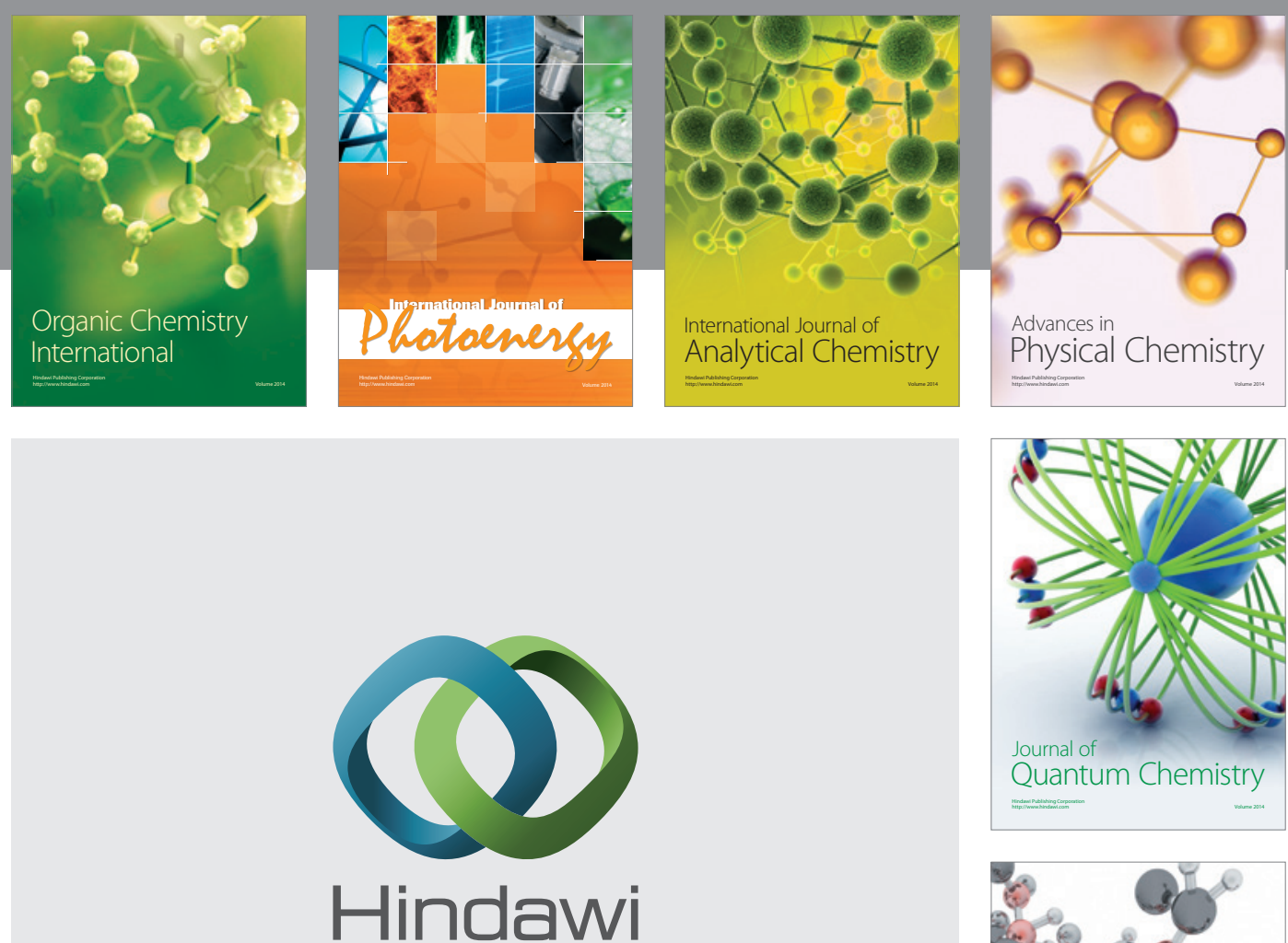

Submit your manuscripts at

http://www.hindawi.com

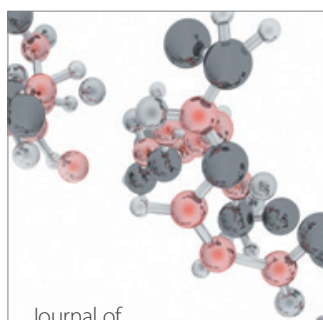

Analytical Methods

in Chemistry

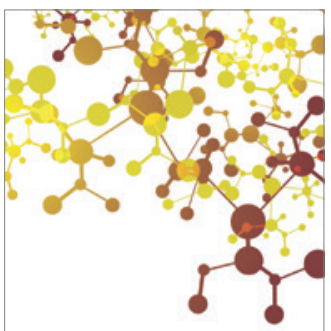

Journal of

Applied Chemistry

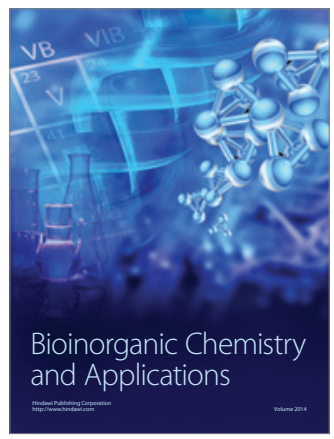

Inorganic Chemistry
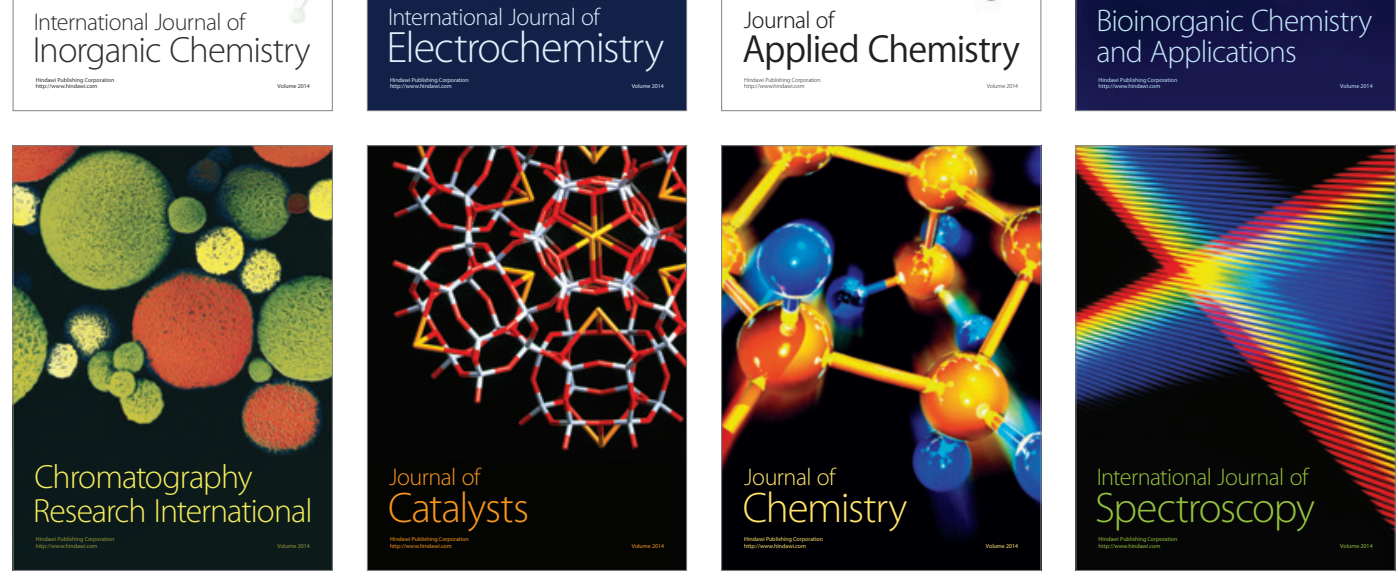